\title{
Risco de infecção pelo vírus da imunodeficiência humana (HIV) em pro- fissionais da saúde
}

\section{Risk of infection by the human immune deficiency virus (HIV) among health professionals}

\author{
Alcyone Artioli Machado", João Carlos da Costa", Elucir Gir"", Tokiko Murakawa Moriya", José \\ Fernando de Castro Figueiredo"
}

MACHADO, A.A. et al. Risco de infecção pelo vírus de imunodeficiência humana (HIV) em profissionais da saúde. Rev. Saúde públ., S. Paulo, 26: 54 - 6 1992. [A fim de investigar o risco ocupacional de infecção pelo vírus da imunodeficiência humana (HIV) em profissionais da saúde, foram estudados 35 casos de acidentes com material potencialmente contaminado pelo HIV, ocorridos em funcionários do Hospital das Clínicas da Faculdade de Medicina de Ribeirão Preto da Universidade de São Paulo (HCFMRP-USP). Dos 36 profissionais de saúde estudados, 52,8\% (19/36) eram auxiliares de enfermagem, $19,4 \%(7 / 36)$ enfermeiras, $13,9 \%$ (5/36) atendentes de enfermagem, e 5,5\% (2/36) técnicos de enfermagem. Em 47,2\% (17/36) dos casos houve exposição parenteral a sangue (acidente com agulha). As mãos e os dedos foram as áreas do corpo mais atingida. Foi empregado o teste imunoenzimático (ELISA) para detecção de anticorpos anti-HIV, sendo realizado em todos os profissionais por ocasião do acidente e com 1,2,6 e 12 meses após a exposição. Os resultados foram negativos não sendo registrada nenhuma soroconversão. Recomenda-se que a educação continuada para o trabalhador de saúde deve reforçar o uso das precauções universais, especialmente os cuidados com agulhas e outros instrumentos perfurantes.

Descritores: HIV. Riscos ocupacionais. Ocupações em saúde.

\section{Introdução}

Paralelamente ao aparecimento de indivíduos com a Síndrome de Imunodeficiência Adquirida (AIDS) foram sendo relatados casos profissionais de saúde que adquiriram o Vírus da Imunodeficiência Humana (HIV) em consequência de sua atividade profissional $1,5,11,12$.

Como mostram os vários relatos da literatura, determinar a circunstância em que ocorreu a contaminação para o profisssional da saúde sempre foi difícil e controvertida ${ }^{4,5,8,9}$. Através de diferentes estudos realizados em outras localidades tem-se que o risco de infecção após uma simples exposição percutânea por sangue infectado pelo HIV é menor que $1 \%, 10,13$.

A presente nota tem o objetivo de mostrar o risco do profissional de saúde no exercício de sua profissão, em adquirir infecção pelo HIV após contato e acidente com material potencialmente contaminado.

\footnotetext{
Departamento de Clínica Médica da Faculdade de Medicina de Ribeirão Preto da Universidade de São Paulo - Ribeirão Preto, SP - Brasil.

** Departamento de Enfermagem Geral e Especializada da Escola de Enfermagem de Ribeirão Preto da Universidade de São Paulo - Ribeirão Preto, SP - Brasil.

Separatas/Reprints: A.A. Machado - Av. Bandeirantes, 3900 - 14049 - Ribeirão Preto, SP - Brasil.

Publicação financiada pela FAPESP. Processo Saúde Coletiva 91/4994-0.
}

\section{Material e Método}

Foram analisados, retrospectivamente, 36 casos de funcionários que sofreram acidente de trabalho por material potencialmente contaminado pelo HIV, notificados ao Serviço Médico do Hospital das Clínicas da Faculdade de Medicina de Ribeirão Preto da Universidade de São Paulo (HCFMRP-USP) no período de junho de 1987 a agosto de 1990. O HCFMRP-USP possuia nesse periodo cerca de 7.000 funcionários.

Os dados dos funcionários quanto à idade, sexo, local e tempo de serviço, tipo de acidente de trabalho, material com o qual foi exposto, região anatômica em que ocorreu o acidente, pesquisa de anticorpos contra HIV no soro e a ocorrência ou não de soroconversão foram coletados junto aos prontuários médicos. A pesquisa de anticorpos anti-HIV foi realizada pelo método imunoenzimático (ELISA), empregando kits comerciais da marca Abbott (Abbott Recombinant HIV-1 EIA).

\section{Resultados e Discussão}

Nos 36 casos estudados, $75 \%(27 / 36)$ dos acidentes ocorreram em profissionais do sexo feminino e $25 \%(9 / 36)$ no sexo masculino. Os profissionais acidentados tinham idade variando de 
23-40 anos (média de 34,6 anos) e 94,6\% (34/36) deles trabalhavam no hospital por um periodo superior a um ano.

A categoria profissional que mais se acidentou com material potencialmente contaminado pelo HIV foi a mais diretamente relacionada com o

Tabela 1. Cargo ocupado pelos profissionais da saúde que sofreram acidente de trabalho com material potencialmente contaminado pelo HIV

\begin{tabular}{lr}
\hline \multicolumn{1}{c}{ Cargo } & № Indivíduos (\%) \\
\hline Auxiliar de Enfermagem & $19(52,78 \%)$ \\
Enfermeiro & $7(19,45 \%)$ \\
Atendente de Enfermagem & $5(13,9 \%)$ \\
Técnico de Enfermagem & $1(2,77 \%)$ \\
Escriturária & $1(2,77 \%)$ \\
Técnico de Laboratório & $2(5,56 \%)$ \\
Instrumentadora & $1(2,77 \%)$ \\
\hline \multicolumn{1}{c}{ Total } & $36(100 \%)$ \\
\hline
\end{tabular}

contato direto com o paciente. Assim, 32/36 $(88,8 \%)$ dos casos ocorreram entre os profissionais de enfermagem e, entre eles, os auxiliares de enfermagem foram os que mais frequientemente relataram o acidente (Tabela 1).

Esses resultados estão provavelmente relacionados à própria estrutura funcional da divisão de enfermagem do HCFMRP-USP. Dessa forma, enquanto às enfermeiras cabem tarefas predominantemente administrativas e às atendentes as tarefas menos complexas no cuidado aos pacientes, são as auxiliares de enfermagem as profissionais mais envolvidas na colheita de sangue e secreções para exame laboratorial e na administração de medicamentos por via parenteral.

A predominância de acidentes em individuos do sexo feminino é também provavelmente reflexo da atividade profissional visto que predominam as mulheres entre os profissionais de enfermagem. Fatores outros, tais como a inexperiência no trabalho parecem ser pouco importantes no determinismo do acidente, pois a maioria dos profissionais que se acidentaram eram funcionários antigos do hospital.

Tabela 2. Região anatômica onde ocorreu o contacto com o material potencialmente contaminado pelo HIV em profissionais da saúde

\begin{tabular}{lc}
\hline \multicolumn{1}{c}{ Região Anatômica* } & $N^{2}$ de Ocorrências \\
\hline Dedos e/ou mãos & 30 \\
Braços & 4 \\
Rosto & 4 \\
Olhos & 3 \\
Boca & 1 \\
Não especificado & 7
\end{tabular}

Tabela 3. Modo de contágio pelo HIV em profissionais de saúde

\begin{tabular}{|c|c|}
\hline Contacto com & $N^{2}$ Indivíduos \\
\hline Agulha & 17 \\
\hline Sangue & 8 \\
\hline Saliva & 3 \\
\hline Escarro & 1 \\
\hline Arranhāo por unha do paciente & 2 \\
\hline Atendimento a parto & 1 \\
\hline Solução de glutaraldeído & 1 \\
\hline Líquido Peritoneal em Diálise & 1 \\
\hline Ampola quebrada & 1 \\
\hline Leite & 1 \\
\hline Nāo especificado & 2 \\
\hline
\end{tabular}

Obs.: Houve profissionais com 2 tipos de contacto

Os acidentes ocorreram predominantemente nas extremidades do corpo (mãos e/ou dedos) e foram consequência principalmente de ferimentos com agulha ou contacto com sangue e secreções corporais do paciente (Tabelas 2 e 3 ).

Apesar de não se dispor de informações sobre as medidas de proteção em uso pelos funcionários no momento do acidente, os dados acima reforçam a necessidade de se manter rigorosa observância das normas de proteção indicadas no cuidado dos pacientes, principalmente quanto ao uso de luvas e a técnica empregada durante a colheita de material ou quando do manuseio de suas secreções.

Com exceção de um funcionário, todos receberam orientação para seguimento clínico e laboratorial após o acidente, seguindo a recomendação dos Centers for Disease Control ${ }^{3}$. Todos eles tiveram uma primeira amostra de sangue colhida entre 0 e 12 dias após o acidente com resultado negativo para anti-HIV.

Um funcionário referia comportamento de risco para a infecção pelo HIV. Durante o seguimento sorológico, 30 funcionários submeteram-se a dois testes, 27 a três testes e 20 a quatro testes. Todos os testes resultaram negativos durante o seguimento, confirmando relatos anteriores ${ }^{6,7,10}$ de que são raros os episódios de soroconversão após acidentes com material potencialmente contaminado pelo HIV.

Apesar disso, e levando em conta os freqüentes aspectos emocionais que se seguem a acidentes dessa natureza, é recomendável manter os profissionais de saúde, mais intensamente expostos ao risco, orientados quanto: 1 . à atual dimensão do problema da AIDS no nosso meio, com ênfase ao contingente de indivíduos infectados e ainda assintomáticos; 2. às formas mais freqüentes de contágio durante a atividade profissional; 3 . à necessidade de obediência irrestrita ás normas de prote- 
ção individual durante as atividades profissionais de rotina.

MACHADO, A.A. et al. [Risk of infection by the human immune deficiency virus (HIV) among health professionals.] Rev. Saúde públ., S. Paulo, 26: $54-6,1992$. To investigate the occupational risk of infection by HIV among health professionals, 36 cases of occupational accidents involving exposure to material potentially infected with HIV, reported at a Brazilian General Hospital (HCFMRP), were studied. Of the injured workers 75\% were female and $25 \%$ male (ranging from 23 to 49 years old) and just one of them had high-risk behavior of HIV infection. Of these health professionals, $52.8 \%$ were nursing auxiliaries, $19.4 \%$, nurses, $13.9 \%$, nursing attendants, $5.5 \%$, laboratory technicians, $2.8 \%$ surgery instrumentalist, $2.8 \%$ accountants and $2.8 \%$ nursing technicians. In $47.2 \%$ of cases the workers had a parenteral exposure to blood (needlestick injuries). The right hand and fingers were the body areas most effected. The serologic test to detect HIV antibodies by the ELISA method was required of all the workers. The results were negative and no seroconversion was registered during the one year follow-up period. The professionals were retested one month, 2 months, 6 months and one year after the exposure. In conclusion, the risk of infection by HIV among health professionals of HCFMRP seems to be very low. Continuing education should be provided for health care workers with a view to reinforcing the use of universal precaution, especially those to prevent injuries cause by needles or other sharp instruments

Keywords: HIV. Working risks. Health occupations

\section{Referências Bibliográficas}

1. ANONYMOUS. Needlestick transmission of HTLV-III from a patient infected in África. Lancet, 2; 1376-7, 1984.

2. CENTERS FOR DISEASE CONTROL (CDC). Guidelines for prevention of transmission of human immunodeficiency virus and hepatitis $B$ virus to health-care and public - safety workers. Morb. Mort. wkly Rep., 38 (S-6): 1-37, 1989.
3. CENTERS FOR DISEASE CONTROL (CDC). Public health service statement on management of occupational exposure to human immunodeficiency vírus, including considerations regarding zidovudine post-exposure use. Morb. Mort. wkly Rep., 39 (RR-1): 1-14, 1990.

4. CENTERS FOR DISEASE CONTROL (CDC). Recommendations for preventions of HIV transmission in health-care settings. Morb. Mort. wkly Rep., 36 (2S): 3S-18S, 1987.

5. CENTERS FOR DISEASE CONTROL (CDC). Update: human immunodeficiency virus infections in health-care workers exposed to blood of infected patients. Morb. Mort. wkly Rep., 36 (19): 285-9, 1987.

6. HEALTH AND WELFARE CANADA. National surveillance program on occupational exposure to HIV among health-care workers. Can. Dis. Wkly Rep, 13: 163-6, 1987.

7. HENDERSON, D.K. et al. Risk of nosocomial infection with human T-cell lymphotropic virus type III lymphadenopathy-associated virus in a large cohort of intensively exposed health care workers. Ann. intern. Med., 104: 644-7, 1986.

8. KLINE, R.S. et al. Low occupational risk for HIV infection for dental profissionals. New Engl. J. Med., 318: 86-90, 1988.

9. McCRAY E. The cooperative needlestick surveillance group. occupational risk of the acquired immunodeficiency syndrome among health care workers. New Engl. J. Med,314: 1127-32, 1986.

10. McENVOY, M. Et Al. Prospective study of clinical, laboratory and ancillary staff with accidental exposures to blood or other body fluids from patients infected with HIV. Brit. med. J., 294: 1595-7, 1987.

11. NEISSON-VERNANT, C. et. at. Needlestick HIV seroconversion in a nurse. Lancet, 2: $814,1986$.

12. OKSENHENDLER, E. et al. HIV infection with seroconversion after a superficial needlestick injury to the finger. New Engl. J. Med., 315: 582, 1986.

13. PUGLIESE, G. \& LAMPINEN, T. Prevention of human immunodeficiency virus infection: our responsibilities as health-care professionals. Amer. J. Infect. Control, 17 (1): 1-22, 1989.

Recebido para publicação em 18/6/1991 Reapresentado em 14/11/1991 Aprovado para publicação em 22/11/1991 